\title{
Prediction of fetal loss by first-trimester crown-rump length in IVF pregnancies: prediction rules to avoid misinterpretation
}

\author{
Siamak Sabour ${ }^{1,2}$
}

Received: 16 January 2017 / Accepted: 1 February 2017 / Published online: 27 March 2017

(C) Springer-Verlag Berlin Heidelberg 2017

I was interested to read the paper by Gabbay-Benziv $\mathrm{R}$ and colleagues published in Arch Gynecol Obstet 2017 Jan. The purpose of the authors was to evaluate the association between small crown-rump length (CRL) and fetal loss $\leq 22$ weeks in IVF pregnancies [1]. All singleton IVF pregnancies within a 5-year period, with a live embryo on first-trimester ultrasound and verified pregnancy outcome were included (397 pregnancies). They reported that total of 64 pregnancies had $\mathrm{CRL} \leq$ tenth percentile for gestational age. The rate of fetal loss in this group was significantly higher than in pregnancies with CRL $>$ tenth percentile (17.2 vs. $6.6 \%, p=0.005, \quad \mathrm{OR}=2.93,95 \%$ CI 1.2-6.7). In both groups, the majority of fetal losses occurred $\leq 10$ weeks of gestation. Based on their conclusion, in IVF pregnancies with a live embryo, a small CRL at 40-80 days' gestation may predict fetal loss [1].

For prediction studies, we need two different cohort data set or at least one cohort dataset splitting that to develop our prediction model and then to validate it. Without validation of prediction models, most of the times, misleading results will be the main outcome of such researches [2-6].

Moreover, statistically significant finding do not have priority to clinically important results for clinical decision making especially in prediction studies. Statistically significant and clinically important are two different issues and in

Siamak Sabour

s.sabour@sbmu.ac.ir

1 Safety Promotion and Injury Prevention Research Center, Shahid Beheshti University of Medical Sciences, Tehran, Islamic Republic of Iran

2 Department of Clinical Epidemiology, School of Health, Shahid Beheshti University of Medical Sciences, Tehran, Islamic Republic of Iran clinical researches, the strength of the relation is more important than $p$ value [2-6].

Finally, in prediction studies, we must assess interaction between important variables because the final result can extremely change in case of having qualitative interaction [2-6]. It means without assessing interaction terms most of the times misleading message will be our main conclusion in prediction studies.

\section{Compliance with ethical standards}

Conflict of interest S. Sabour declares that he has no conflict of interest.

Ethical approval This article does not contain any studies with human participants performed by any of the authors.

\section{References}

1. Gabbay-Benziv R, Dolev A, Bardin R, Meizner I, Fisch B, BenHaroush A (2017) Prediction of fetal loss by first-trimester crown-rump length in IVF pregnancies. Arch Gynecol Obstet. doi:10.1007/s00404-016-4266-8 (Epub ahead of print)

2. Rothman KJ, Sander G, Timothy LL (2008) Cohort studies. In: Rothman KJ. Modern epidemiology, 3rd edn, Lippincott Williams \& Wilkins, Baltimore, p 79-85

3. Sabour S (2015) Prediction of preterm delivery using levels of VEGF and leptin in amniotic fluid from the second trimester: prediction rules. Arch Gynecol Obstet 291(4):719. doi:10.1007/s00404-0143568-y (Epub 2014 Dec 10)

4. Sabour S (2015) Prediction of 3-dimensional pharyngeal airway changes after orthognathic surgery: a methodological issue. Am J Orthod Dentofacial Orthop 147(1):8. doi:10.1016/j. ajodo.2014.10.016

5. Sabour S (2014) Obesity predictors in people with chronic spinal cord injury: a common mistake. J Res. Med Sci 19(1):80

6. Sabour S, Ghassemi F (2013) Predictive value of confocal scanning laser for the onset of visual field loss. Ophthalmology 120(6):e31-e32. doi:10.1016/j.ophtha.2013.01.055 